Supporting Information for:

\title{
DNA-like Photophysics in Self-Assembled Silver(I)-Nucleobase Nanofibers
}

\author{
Joshua A. Snyder, Aaron P. Charnay, Forrest R. Kohl, Yuyuan Zhang and Bern Kohler
} Department of Chemistry and Biochemistry, The Ohio State University, 100 West 18th Avenue,

Columbus, Ohio 43210 


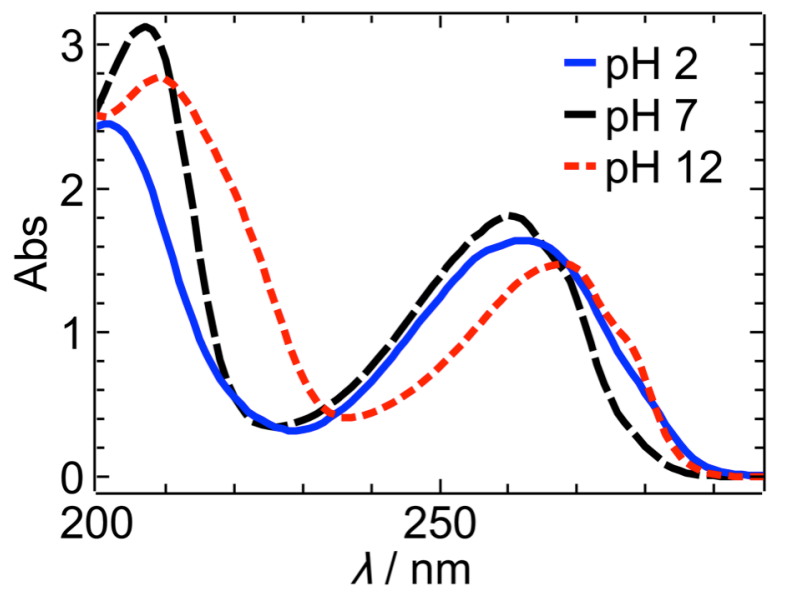

Figure S1. UV-vis spectra of Adenine at the indicated $\mathrm{pH}$ values.

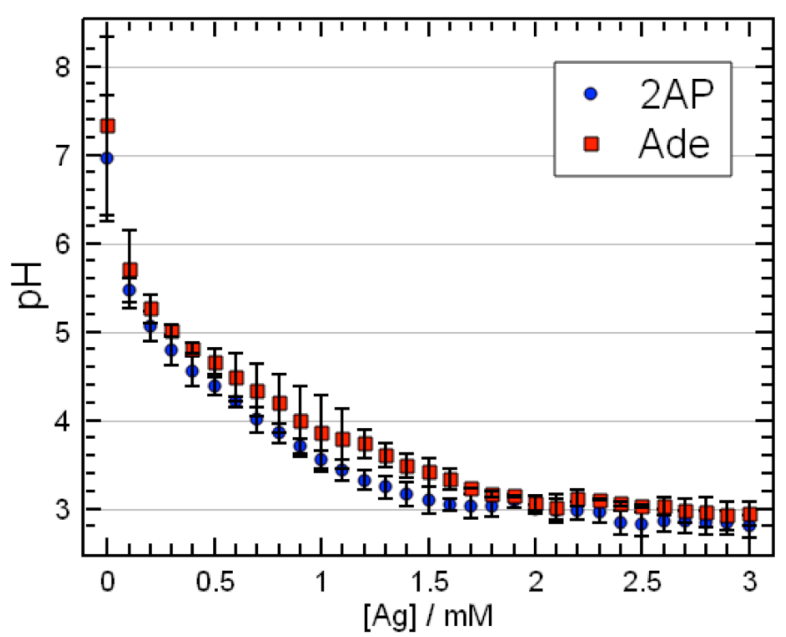

Figure S2. $\mathrm{pH}$ dependence following titration of $2 \mathrm{AP}$ and Ade solutions $(1 \mathrm{mM})$ with $\mathrm{AgNO}_{3}$. The error is reported with a $95 \%$ confidence interval calculated from two trials. 


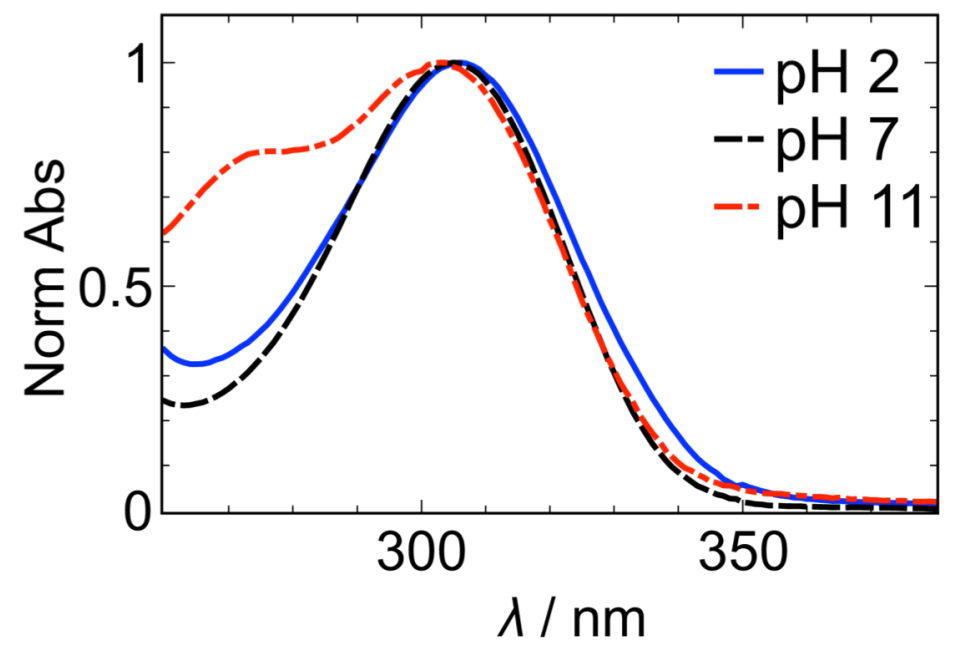

Figure S3. UV-vis absorption spectra (normalized) of $2 \mathrm{AP}$ at the indicated $\mathrm{pH}$ values.

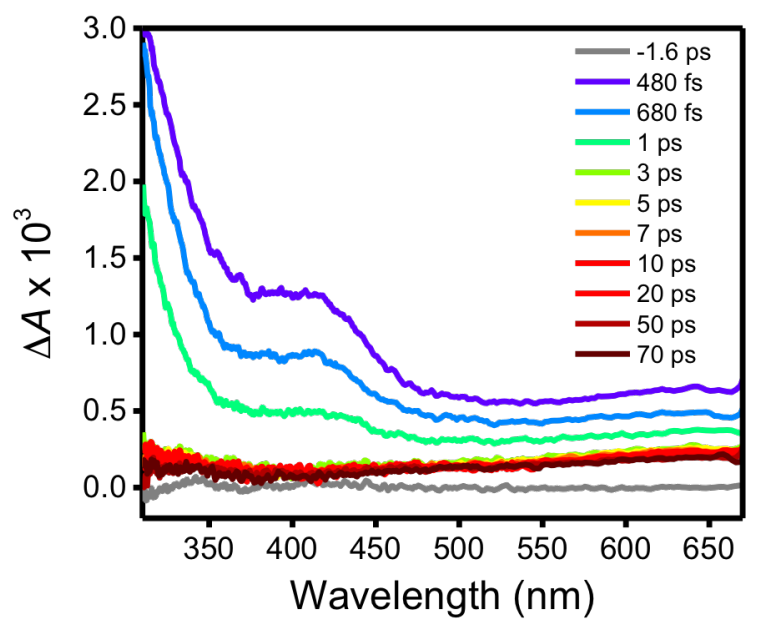

Figure S4. Broadband fs-TA spectra of Ade at $\mathrm{pH} 12.5$ following photoexcitation at $265 \mathrm{~nm}$ at the indicated delay times. 


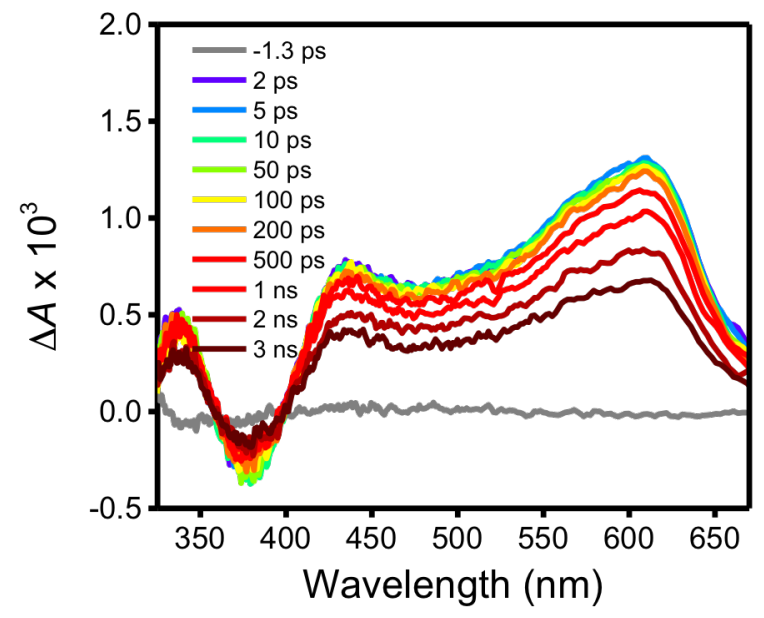

Figure S5. Broadband fs-TA spectra of $2 \mathrm{AP}$ at $\mathrm{pH} 12.5$ following photoexcitation at $300 \mathrm{~nm}$ at the indicated delay times. Lifetimes of $1.5 \pm 0.1 \mathrm{ps}$ and $>3$ ns were determined by global analysis.

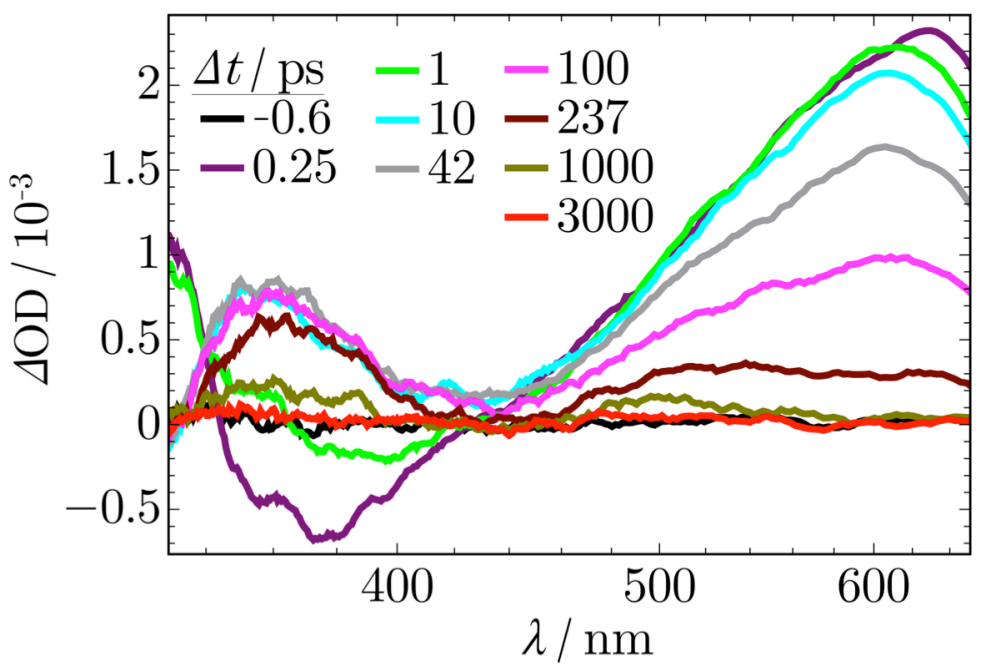

Figure S6. Broadband fs-TA spectra of $2 \mathrm{AP}$ at $\mathrm{pH} 2$ following photoexcitation at $300 \mathrm{~nm}$ at the indicated delay times. Lifetimes of $2.3 \pm 0.4,100 \pm 4$ and $610 \pm 50$ ps were determined by global analysis. 


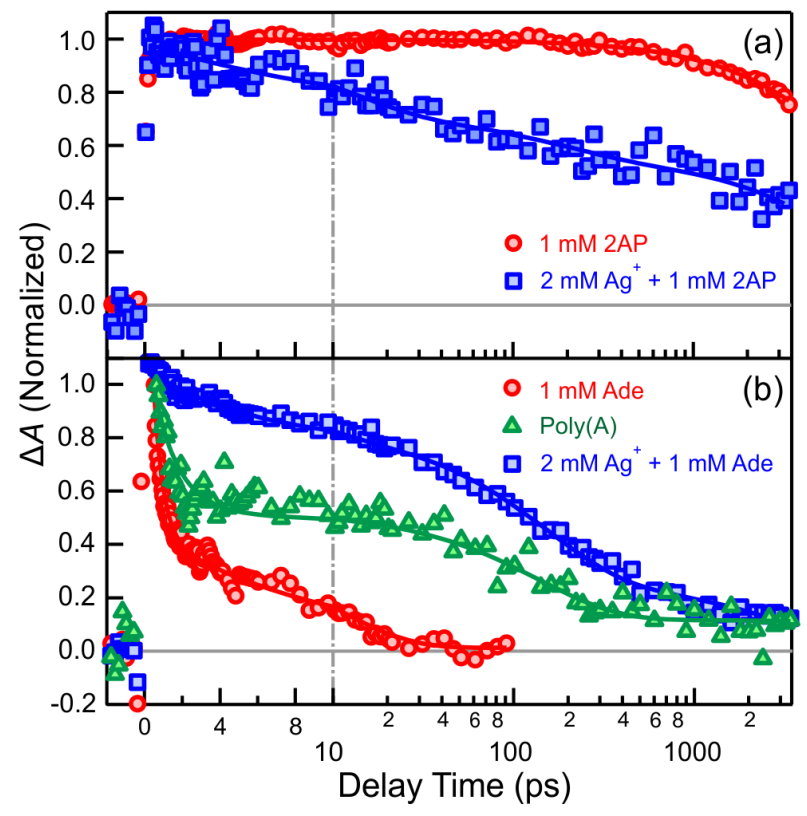

Figure S7. Normalized fs-TA kinetic traces of the free nucleobases (red circles) and the $\beta=2$ $\mathrm{Ag}^{+} /$nucleobase assemblies (blue squares) for (a) 2AP (pump $300 \mathrm{~nm} /$ probe $540 \mathrm{~nm}$ ) and (b) Ade (pump $265 \mathrm{~nm} / 360 \mathrm{~nm}$ probe). The trace for poly(A) probed at $360 \mathrm{~nm}$ is shown by green triangles in panel b. Fit curves are obtained from global analysis (see Table 1). The vertical gray dash-dotted line indicates the linear-logarithmic break in the time axis.
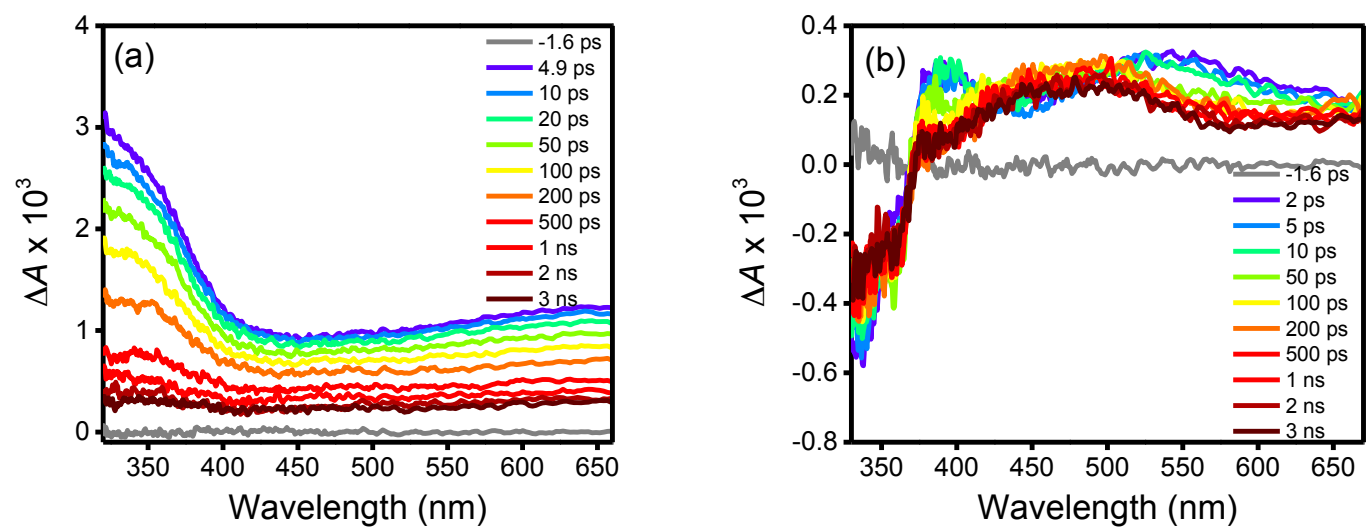

Figure S8. Broadband fs-TA spectra at the indicated delay times for (a) $\operatorname{Ag}^{+} / \operatorname{Ade}(\beta=1)$ in $\mathrm{H}_{2} \mathrm{O}$ at $\mathrm{pH} 3$ following $265 \mathrm{~nm}$ excitation, and (b) $\mathrm{Ag}^{+} / 2 \mathrm{AP}(\beta=1) \mathrm{in}_{2} \mathrm{O}$ at $\mathrm{pH} 3$ following $300 \mathrm{~nm}$ excitation. The pump fluences are identical to those used for the measurements on the $\beta=2$ solutions (see Figures 4c, $5 \mathrm{~b}$ in the main text). 

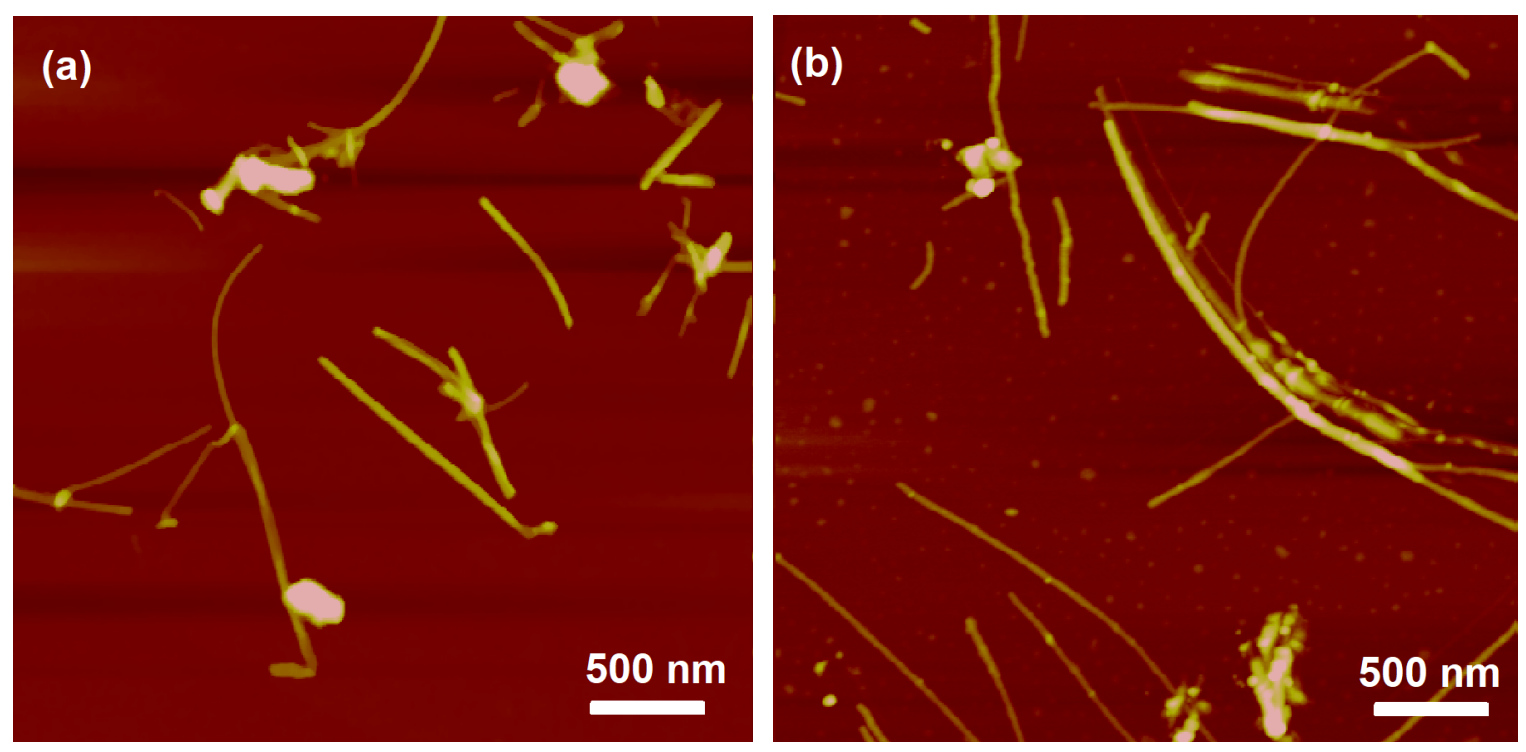

Figure S9. AFM images recorded at room temperature of (a) $\mathrm{Ag}^{+} / 2 \mathrm{AP}(\beta=1)$ and (b) $\mathrm{Ag}^{+} / \mathrm{Ade}^{-}$ $(\beta=1)$ solutions drop cast on mica after solvent evaporation.

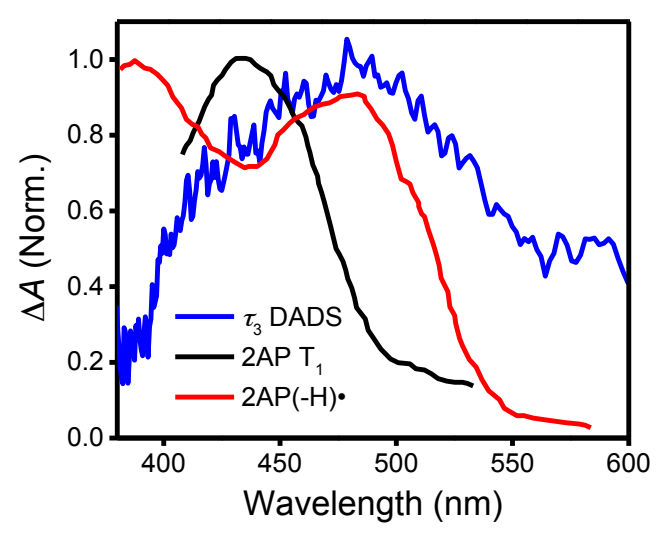

Figure S10. Comparison of the long-time DADS ( $\tau_{3}$ from Figure $5 \mathrm{~d}$ ) $\mathrm{of}^{\mathrm{Ag}} / 2 \mathrm{AP}$ at $25{ }^{\circ} \mathrm{C}$ to literature spectra of triplet $2 \mathrm{AP}\left(\mathrm{T}_{1}\right.$ state $)$ and $2 \mathrm{AP}(-\mathrm{H})^{\circ}$ from references $1-2$, respectively. 


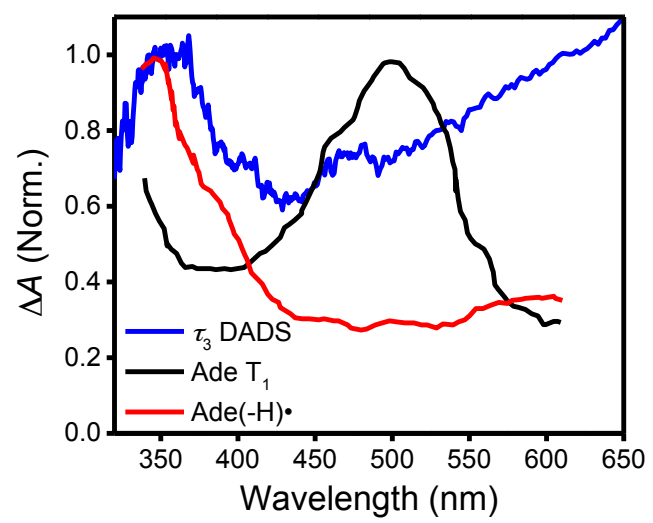

Figure S11. Comparison of long time DADS ( $\tau_{3}$ from Figure 4f) of $\mathrm{Ag}^{+} / \mathrm{Ade}$ to literature spectra of the lowest triplet state of Ade and Ade(-H) ${ }^{*}$ digitized from references 3-4, respectively. 
Table S1. Free $\mathrm{Ag}^{+}$concentration in $\mathrm{Ag}^{+} / \mathrm{Ade}$ at various $\beta$ values ([Ade] was held constant at 1 $\mathrm{mM}$ ) measured by the $\mathrm{Ag}^{+}$-selective electrode. See Experimental section in the main text for details.

\begin{tabular}{c|c}
\hline$\beta$ & {$\left[\mathrm{Ag}^{+}\right]_{\text {free }}(\mathrm{mM})$} \\
\hline $0.00-0.60^{a}$ & $<5 \times 10^{-3}$ \\
0.70 & $7.2 \times 10^{-3}$ \\
0.79 & $1.3 \times 10^{-2}$ \\
0.89 & $2.3 \times 10^{-2}$ \\
0.99 & $3.8 \times 10^{-2}$ \\
1.09 & $5.9 \times 10^{-2}$ \\
1.19 & $9.1 \times 10^{-2}$ \\
1.29 & 0.13 \\
1.39 & 0.18 \\
1.49 & 0.25 \\
1.59 & 0.32 \\
1.69 & 0.40 \\
1.79 & 0.49 \\
1.89 & 0.58 \\
1.99 & 0.66 \\
2.48 & 1.2 \\
2.98 & 1.7 \\
3.97 & 2.7 \\
4.97 & 3.8 \\
5.96 & 4.8 \\
\hline
\end{tabular}

${ }^{a}$ For $0 \leq \beta \leq 0.60$, the measured free $\mathrm{Ag}^{+}$concentration was below the minimum sensitivity of the electrode $(5 \mu \mathrm{M})$. 
Table S2. Free $\mathrm{Ag}^{+}$concentration in $\mathrm{Ag}^{+} / 2 \mathrm{AP}$ at various $\beta$ values ([2AP] was held constant at 1 $\mathrm{mM}$ ) measured by the $\mathrm{Ag}^{+}$-selective electrode. See Experimental section in the main text for details.

\begin{tabular}{c|c}
\hline$\beta$ & {$\left[\mathrm{Ag}^{+}\right]_{\text {free }}(\mathrm{mM})$} \\
\hline $0.00-0.80^{a}$ & $<5 \times 10^{-3}$ \\
0.90 & $7.1 \times 10^{-3}$ \\
1.00 & $1.1 \times 10^{-2}$ \\
1.10 & $1.7 \times 10^{-2}$ \\
1.20 & $2.7 \times 10^{-2}$ \\
1.30 & $5.0 \times 10^{-2}$ \\
1.40 & $8.3 \times 10^{-2}$ \\
1.50 & 0.14 \\
1.60 & 0.22 \\
1.70 & 0.31 \\
1.80 & 0.39 \\
1.90 & 0.48 \\
2.00 & 0.59 \\
2.50 & 1.1 \\
3.00 & 1.6 \\
3.50 & 2.2 \\
4.00 & 2.7 \\
5.00 & 3.8 \\
6.00 & 4.8 \\
\hline
\end{tabular}

${ }^{a}$ For $0 \leq \beta \leq 0.80$, the measured free $\mathrm{Ag}^{+}$concentration was below the minimum sensitivity of the electrode $(5 \mu \mathrm{M})$.

\section{References}

1. Reichardt, C.; Wen, C.; Vogt, R. A.; Crespo-Hernández, C. E., Role of intersystem crossing in the fluorescence quenching of 2-aminopurine 2'-deoxyriboside in solution. Photochem. Photobiol. Sci. 2013, 12, 1341-1350.

2. Shafirovich, V.; Dourandin, A.; Huang, W.; Luneva, N. P.; Geacintov, N. E., Oxidation of Guanine at a Distance in Oligonucleotides Induced by Two-Photon Photoionization of 2Aminopurine. J. Phys. Chem. B 1999, 103, 10924-10933.

3. Wood, P. D.; Redmond, R. W., Triplet State Interactions between Nucleic Acid Bases in Solution at Room Temperature: Intermolecular Energy and Electron Transfer. J. Am. Chem. Soc. 1996, 118, 4256-4263.

4. Banyasz, A.; Ketola, T.-M.; Muñoz-Losa, A.; Rishi, S.; Adhikary, A.; Sevilla, M. D.; Martinez-Fernandez, L.; Improta, R.; Markovitsi, D., UV-Induced Adenine Radicals Induced in DNA A-Tracts: Spectral and Dynamical Characterization. J. Phys. Chem. Lett. 2016, 7 , 3949-3953. 